\title{
Integrated Operational Logistics Network (IOLN) Design (Case Study: Iran Khodro Automotive Co) (Phase I)
}

\footnotetext{
Mahmood Majd ${ }^{1}$, Mohammad Reza Motamed $^{2}$, Mohammad Rouhina ${ }^{3}$, and Javad Khamisabadi ${ }^{4, *}$

${ }^{1}$ Director of Logistics Engineering, IKCO, Tehran, Iran

${ }^{2}$ IKCO-Peugeot CEO, Tehran, Iran

${ }^{3}$ Director of Systems Management, IKCO, Tehran, Iran

${ }^{4}$ Expert of Logistics Engineering, ISEIKCO, Tehran, Iran

Board Member at Young Scientists Scientific Center \& Honorary Prof, Kharkov,

Ukraine

Member of Industrial Engineering and Operation Management Society,

Washington, USA

Board Member at WASTINC, Las Vegas, Nevada, USA

Board Member at Entrepreneurship Scientific Center, Moscow, Russia

Board Member at Management Scientific Center, WBS Torun University, Poland

Board Member at IAOES, London, UK

Member of Committee at WEASC, Athens, Greece

Board Member at Supply chain management Scientific Center, Sandy Bay,

Australia

Board Member at Management Scientific Center, AirLanga University, Indonesia

Faculty of Management, Islamic Azad University, Tehran, Iran

E-mail: Javad_khamisabadi@yahoo.com

* Corresponding Author
}

Received 04 December 2018; Accepted 05 December 2018

Publication 24 December 2018

Journal of Industrial Engineering and Management Science, Vol. 1, 39-62.

doi: 10.13052/jiems2446-1822.2018.003

This is an Open Access publication. (c) 2018 the Author(s). All rights reserved. 


\section{Abstract}

Logistics Engineering has transcended over the decades into an approach for competitive benefits in organisational performance and logistics efficiency. Most industries are recognising that significant savings are available to companies that are able to ordinate and improve within their logistics operations. Companies today face great challenges because the successful supply of many products and services needs to the effective integration of logistics activities across a prolongation supply chain and an increasing geographical separation. Moreover, logistics integration approach involves both internal integration for an ordinated, unified process as well as relationships to react flexibly, changeability, and responsibility to customer's demands. In this study, by using of Fuzzy Vikor (F-Vikor), the best combination of RIR was selected and RIR Locating was done. The main aim of this paper is survey and design of the integrated operational logistics network (IOLN) and also, a proposed IOLN to integration of the Iran Khodro Co Supply Network. The results show that the optimal combination of RIR was selected as follows: HUB, CRD and RPP. In addition, the most optimal locations were chosen I each logistics operational zone (LOZ), as follows:

LOZ-2: Shahrud (RPP) and Mayamey (CRD)

C-LOZ (Center and North Section): Garmsar (RPP)

C-LOZ: Robat Karim (HUB)

C-LOZ (Center and South Section): Kashan (RPP)

LOZ-3: Bostanabad (RPP) and Zanjan (CRD)

Keywords: Logistics, Supply Chain, Integrated, Fuzzy Vikor, Network, Iran Khodro Co.

\section{Introduction}

Logistics integration is known to improve efficiencies, performance and competitiveness. The integration approach involves both internal and external integration. Internal integration involves the ordinated, coaction and integration of logistics operations with other operational areas in a company; whereas external integration needs to the integration of logistics operations with those of their Demanders and suppliers in the supply chain [1]. Most definitions of supply chain management explicitly recognize the existence of 
two flows through the chain; there is a flow of goods and an equally important flow of information [2]. Supply chain integration must thus comprise both information and material, and cannot restrict itself to only one. Higher levels of integration are characterized by increased logistics-related communication, greater coordination of the firm's logistics activities with those of its suppliers and customers, and more blurred organizational distinctions between the logistics activities of the firm and those of its suppliers and customers [3].

Logistics integration refers to specific logistics practices and operational activities that coordinate the flow of materials from suppliers to customers throughout the value stream $[12,13]$. Logistics provides industrial firms with time and space utilities, by providing the necessary quantity of goods be in the right place at the right time [6]. Grounded on earlier research, the theoretical construct of logistic integration is derived to include the seamless integration of the logistics function of the various supply chain partners [8].

\section{Literature Review}

A literature review or narrative review is a type of review article. A literature review is a scholarly paper, which includes the current knowledge including substantive findings, as well as theoretical and methodological contributions to a particular topic.

\subsection{Supply Chain}

A supply chain is a system of organizations, people, operations, information, and resources involved in moving a series of materials, goods, final Products or services from suppliers to end users. Supply chain activities involve the transformation of natural resources, raw materials, into a final product that is delivered to the customer [5].

\subsection{Logistics}

It is the function that ensures the flow of materials from suppliers into an organisation, through operations within an organisation and then outward to customers. Products can be either physical, tangible goods or invisible services e.g. the Namibian Diaries delivers tangible goods such as milk, cheese and cream to the country. Cell one and Telecom provide invisible services to their customers or a combination of goods and services $[12,13]$. 


\subsection{The Role of Logistics}

The role of logistics is to ensure the smooth and efficient flow of materials from the point of origin through the manufacturing process (operations) right up to the end user. Moving materials into the organisation from source suppliers is the activity known as inbound logistics (inward logistics). Moving materials within the organisation is the activity we call materials management. On the other hand, moving materials out to customers is the activity known as outbound logistics (outward logistics). In practice, logistics is used to move both tangible and intangible products such as information, messages, programmes transmission, entertainment, finished products, work in progress, people, paperwork, energy, money and minerals [8].

\subsection{Inbound Logistics (Inward Logistics)}

Which involve relationships with suppliers and include all the activities required to receive, store and disseminate inputs.

\subsection{Outbound Logistics (Outward Logistics)}

Which involve relationships with customers and include all the activities required to collect, store and distribute the output [8].

\subsection{Operations}

Are all the activities required to transform inputs into outputs (products and services) $[12,13]$.

\subsection{Push Strategies}

A push-model logistics is one where projected demand determines what enters the process. For example, warm jackets get pushed to clothing retailers as summer ends and the fall and winter seasons start. Under a push system, companies have predictability in their supply chains since they know what will come when - long before it actually arrives. This also allows them to plan production to meet their needs and gives them time to prepare a place to store the stock they receive.

\subsection{Pull Strategies}

A pull strategy is related to the just in time in inventory management that minimizes stock on hand, focusing on last-second deliveries. Under these 

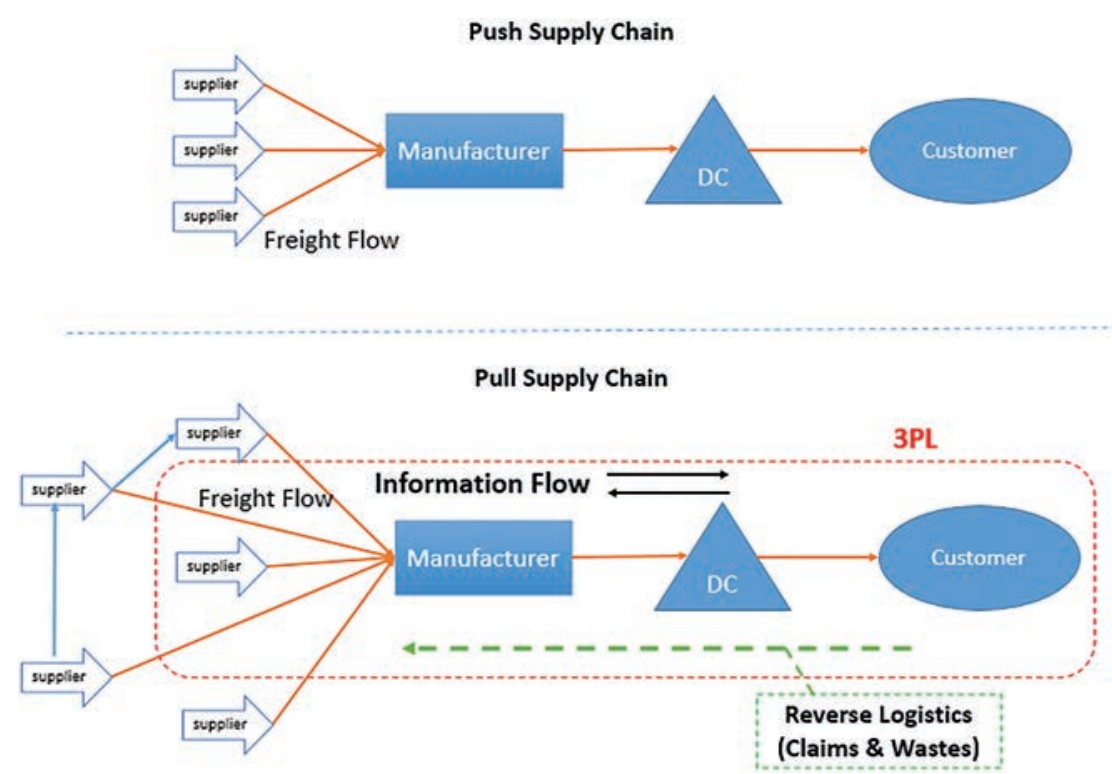

Figure 1 Pull and Push Supply Chain.

strategies, products and goods enter the supply chain when customer demand justifies it. One example of an industry that operates under this strategy is a direct computer seller that waits until it receives an order to actually build a custom computer for the consumer. With a pull strategy, companies avoid the cost of carrying inventory that may not sell. The risk is that they might not have enough inventory to meet demand if they cannot ramp up production quickly enough.

\subsection{Supply Chain and Logistics Integration}

Integration can be defined as the combining and coordinating of separate parts or elements into a unified whole. "The unified control of a number of successive or similar economic or especially industrial processes formerly carried on independently". They further illustrate that firms who are not internally integrated comprise logistics activities as fragmented and often uncoordinated, and spread throughout various organizational functions with each individual function having its own budget and its own set of priorities and measurements [16]. 


\subsection{Internal Supply Chain Integration}

The phrase 'internal (or micro) supply chain' has appeared in the literature to describe work aimed at breaking down the barriers between functions within organisations. To establish a framework for describing the key functions of a typical internal supply chain, SCM "revolves around the buying, making, moving and selling of 'stuff' " is quite instructive. It is in line with the 'buymake-move-sell' model of product supply chains introduced earlier. For the purposes of this section the author has added a fifth element, namely the 'store' activity. This has been done to ensure that all activities associated with the design and management of warehouses and other storage locations is given due recognition in the framework. Warehouse management has long been regarded as an integral element of the logistics activity of firms and a significant amount of specialist knowledge and expertise in this area has been developed over the years. Essentially, 'move' has been disaggregated into separate 'move' and 'store' elements, reflecting the specific characteristics of each of these activities. The main elements of internal supply chain are: buy, make, store, move and sell [3].

\subsection{Inbound-Outbound Integration}

Means unifying functions and processes within the firm especially in the areas of warehousing, transportation, inventory management, purchasing, demand planning and production. In order to integrate internal operations, firms need to have cross-functional structures because cross-functional inputs necessitate the consideration of how coordination and integration can be sustain across this intra-firm relationship. This can be achieve with an appropriate organizational structure with fewer formalities, more empowerment and work teams [17]. The nature of logistics is such that it involves intricacy, extensive documentation and detailed management. There is a need to streamline operations and redesign work routines and processes to eliminate redundancy of work.

This allows savings of cost and time, and increases the quality of services, and ultimately value to customers [9].

\subsection{Stages in Logistics Integration}

Seven stages towards integration of logistics operations. Integration within an organisation typically goes the following stages:

Stage 1-separate logistics functions are not given much attention or considered important. 
Stage 2 - recognizing that the separate functions of logistics are important for the success of the company.

Stage 3 - making improvements of the separate functions, making sure that each one is efficient as possible.

Stage 4 - internal integration (recognizing the benefits of the internal cooperation and combining the separate operations, into one).

Stage 5 - developing and improving a Logistics Planning, to set the long-term direction of logistics.

Stage 6 - benchmarking, comparing logistics' performance with other Organizations, learning from their experiences, identifying areas that need improvements and developments and finding ways of achieving this.

Stage 7 - continuous improvement and development, accepting that further changes are inevitable and always searching for better ways of organizing logistics [14].

\subsection{Benefits of Logistics Integration}

1. Genuine co-operation between all parties of supply chain with shared information and resources.

2. Lower total logistics costs due to balanced operations, lower stocks, less expediting, economics of scale, and elimination of acts, which waste time and do not add value.

3. Improved performance due to more accurate, better planning, higher productivity and prioritization.

4. Improved material and goods flow and handling, with better coordination giving faster and more reliable movements.

5. Better customer service with shorter lead times, faster deliveries and more customization.

6. More flexibility with organizations reacting faster to changing conditions.

7. More standardized procedures, becoming routine and well-practiced with less duplication of effort, information and planning.

8. Reliable quality and few inspections, with integrated quality management programs [1].

\section{Problem Statement}

In order to achieve efficient supply chain integration for the processes or activities; the organizations should recognize and understand all the integration 
challenges of supply chain. The main aim of this paper is survey and design of the integrated operational logistics network (IOLN) and also, a proposed IOLN to integration of the Iran Khodro Co Supply Network. The reason behind introducing those challenges is the absence of a single source in the literature able to present all those challenges in an organized and complete manner. This work needs to integrate all supply chain integration challenges research findings. One of the major challenges Iran Khodro Co, which is active in the automotive industry in Iran, is the integration of supply chain and logistics networks. There are many goals in this regard, but most important are creation of an integrated engineering system for the delivery of raw materials, production of products and distribution to the final customer. Considering the geographical scope of Iran and dispersion of manufacturing sites and suppliers, in this research, we attempt to create and design a comprehensive logistics network; through creation of hubs, cross-dock and Pool Points, material flow Primary and products across the logistics network will shift the existing push logistics system to the pull logistics system. We should gradually move towards Pull-Push logistics system to increasing flexibility in market demand, connect with more suppliers, consider alternative suppliers and dependence on specific suppliers, streamline information across the supply chain, increase coordination and integration. The supply chain components are created through creation of a logical loop, as well as creation of return relationships related to the flow of unloaded pallets and parts. For instance, a company may choose to stockpile finished product at its distribution centres to wait for orders that pull them to stores. Manufacturers might choose to build up inventories of raw materials - especially those that go up in price -

knowing that they will be able to use them for future production. The important specifications of Pull-Push (Hybrid) logistics system are:

1. Production Precision

2. Optimize Material Flow

3. Inventory and Stock Reduction

4. Waste Reduction

5. Create better information flow loop

6. Close relationship and more coordination between elements of supply chain

7. Small lots

8. Optimize pallets flow and tracking

9. Extra trips reduction 


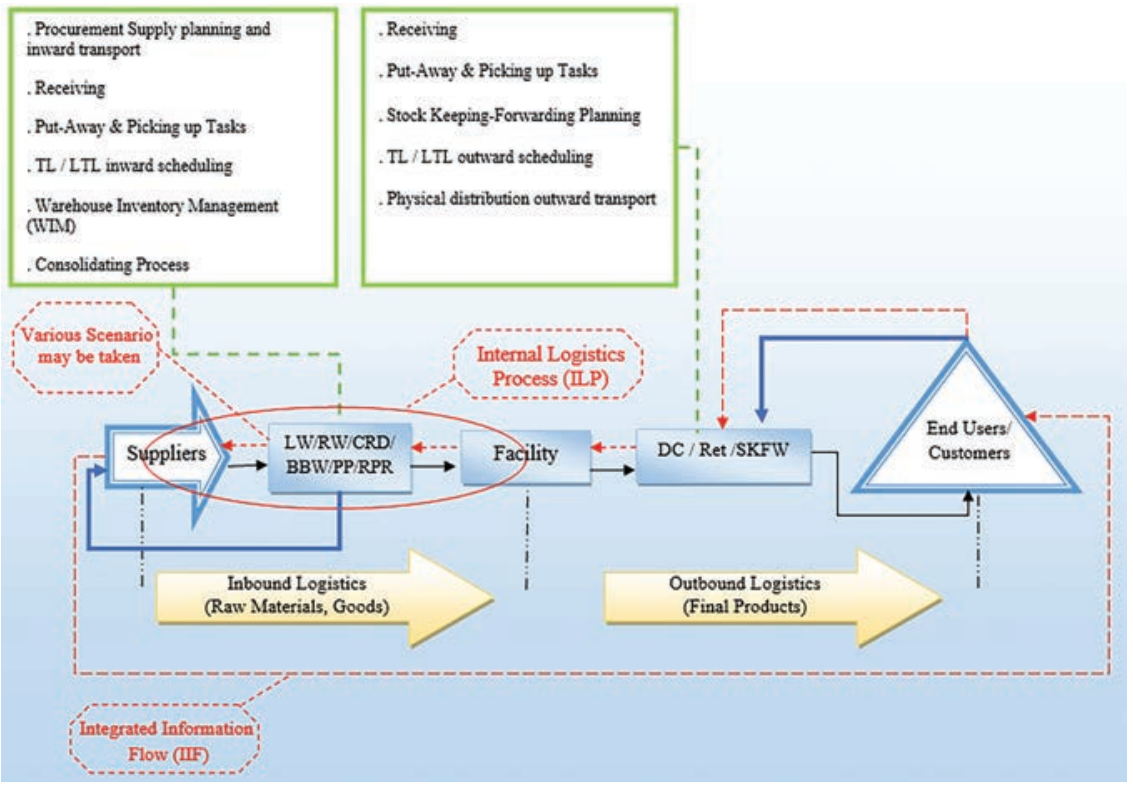

Figure 2 Designed Integrated Logistics.

10. Improve Warehousing and the ability to successful implement of warehousing systems, including kitting system

11. Create and design an efficient integrated supply chain.

\section{Methodology}

At this stage of the research, firstly, the identification of the sites and suppliers of Iran Khodro Co. Then the geographic coordinates of each of them will be specified on the map. Then the flow of inventory will be determined between each of the manufacturing sites and suppliers. Then bottlenecks are identified at the supply chain level, and then the main indicators for choosing the RIR and their location will be deducted and using the decision making methods in management, their calculations will be carried out. Then, the type and mode of communication between each RIR to integrate the logistics network will be determined based on network analysis techniques. In the next step, the integrated logistics network will be designed and created. In the final step, the evaluation of the design of the design chain will be based on Key Performance Indicator (KPI), and then it will try to continuously improve 


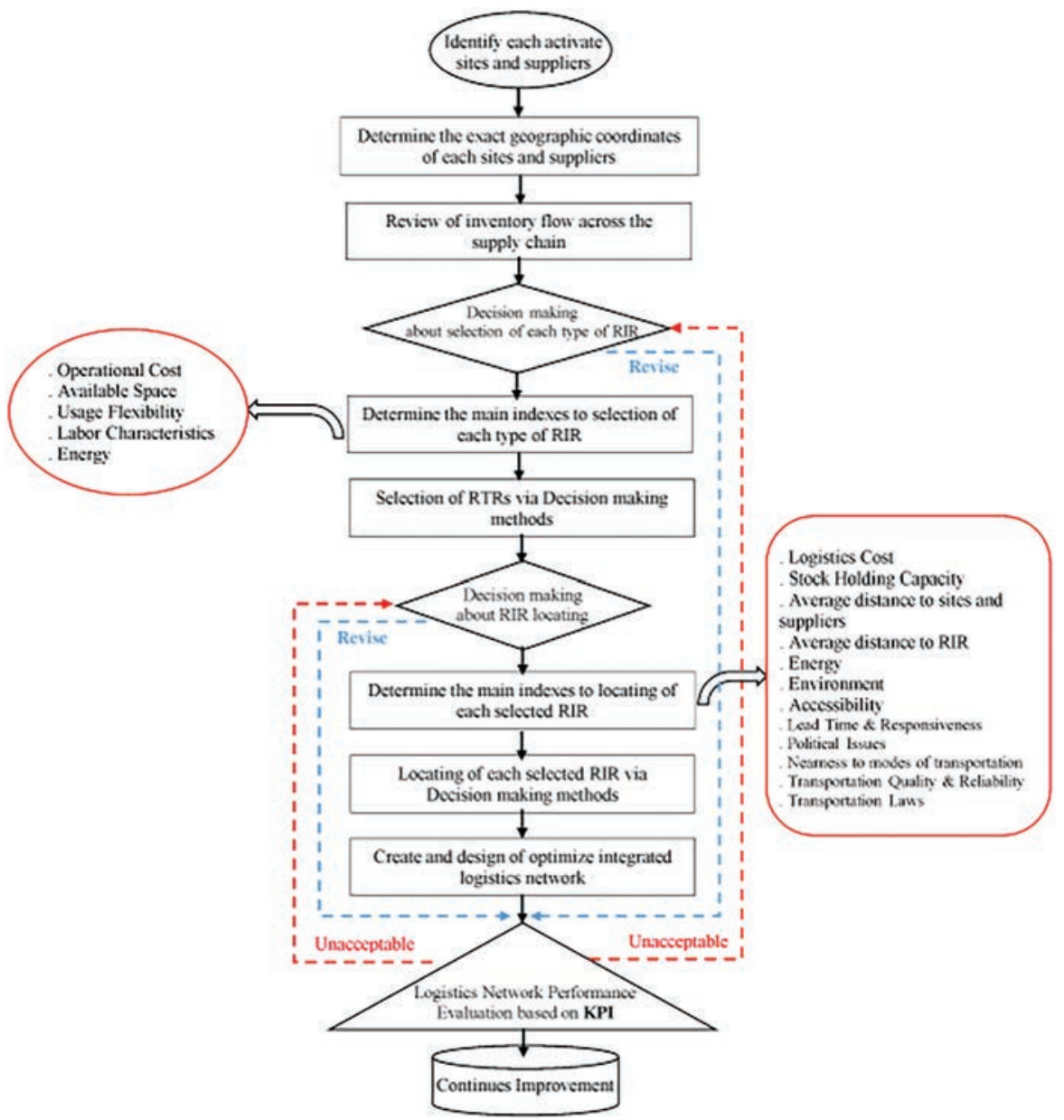

Figure 3 Operational steps to design of IOLN.

the integrated logistics network. The operational steps to design of IOLN are shown in Figure 3.

\subsection{What is Regional Integrator Regulators (RIR)?}

These include various types of logistic operational centers at the level of the supply chain, each of which has different capabilities are based on various 
indicators such as operating cost, available space, flexibility, employee characteristics, and energy. The list of RIR and RIR combination that considered as alternatives is shown in Table 1 . Given the need to create a central hub to integrate the logistics network, the hub as a fixed member, is consider in various RIR combinations.

Table 1 The list of RIR and Alternatives

\begin{tabular}{llcl}
\hline Abbreviation & RIR & Alternative & Combination of RIR \\
\hline CRD & Cross Dock & A1 & Hub, CRD, DC \\
DC & Distribution Center & A2 & Hub, CRD, SKFW \\
SKFW & Stock Keeping-Forward Warehouse & A3 & Hub, CRD, PP \\
RPFR & Regional Pallet Flow Regulator & A4 & Hub, CRD, BBW \\
LPFR & Local Pallet Flow Regulator & A5 & Hub, DC, SKFW \\
BBW & Break Bulk Warehouse & A6 & Hub, DC, PP \\
RW & Regional Warehouse & A7 & Hub, DC, BBW \\
RPP & Regional Pool Point & A8 & Hub, PP, SKFW \\
CPP & Central Pool Point & A9 & Hub, PP, BBW \\
RH & Regional Hub & A10 & Hub, SKFW, BBW \\
CH & Central Hub & & \\
PP-RPP & Pool Point-Regional Pool Point & & \\
\hline
\end{tabular}

Table 2 The list of Manufacturing Sites and their Locations

\begin{tabular}{ll}
\hline Manufacturing Sites & Location \\
\hline IKCO-Tehran & Tehran \\
IKCO-Khorasan & Binaloud \\
IKCO-Tabriz & Tabriz \\
IKCO-Kermanshah & Sahneh \\
IKCO-Mazandaran & Babol \\
Khodrosazi Farda & Semnan \\
IKCO-Fars & Shiraz \\
\hline
\end{tabular}

Table 3 Alternatives cities to choose RIR in each logistics operational zone (LOZ)

\begin{tabular}{lllll}
\hline & & \multicolumn{2}{c}{ Candidate in C-LOZ } & \\
\cline { 3 - 4 } Alternatives & Candidate in LOZ-2 & Center and & South & \\
\hline A1 & Kangavar & Garmsar & Qom & Sabzevar \\
A2 & Takestan & Robat Karim & Kashan & Bardeskan \\
A3 & Zanjan & Varamin & Isfahan & Neyshabur \\
A4 & Mahneshan & Aradan & Shahreza & Jalilabad \\
A5 & Mianeh & Babol & Abadeh & Shahrud \\
A6 & Bostanabad & Firuzkuh & Marvdasht & Mayamey \\
\hline
\end{tabular}




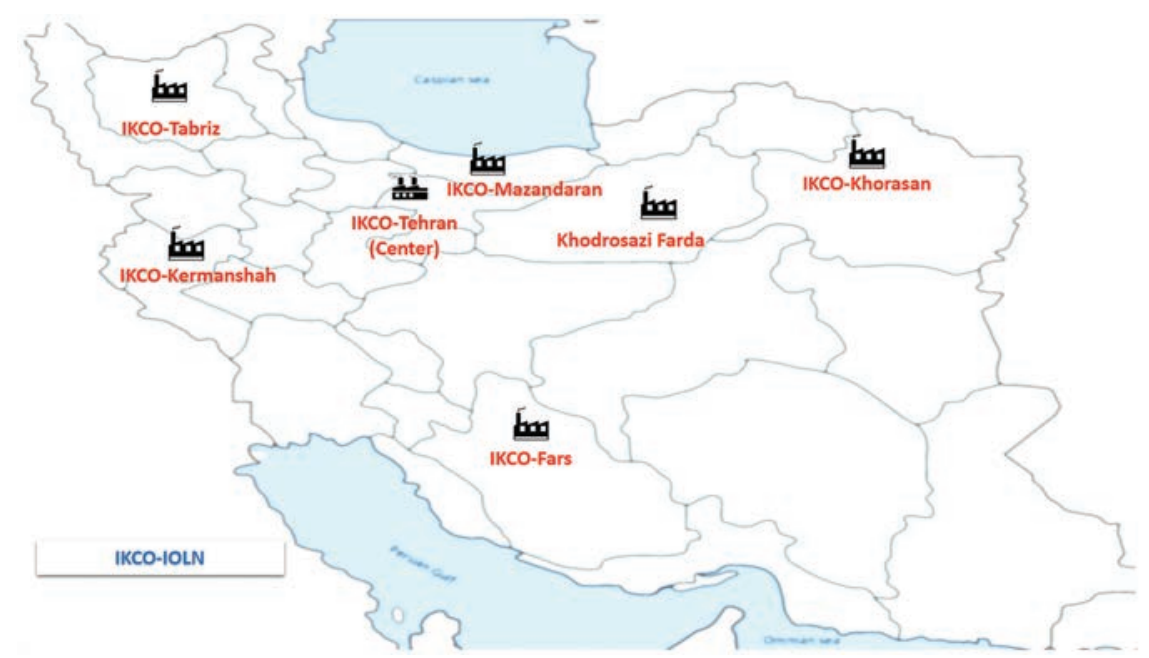

Figure 4 IKCO Manufacturing Sites Glance.

\section{Fuzzy Set Theory}

Zadeh (1975) first developed fuzzy set theory when he was attempting to solve fuzzy phenomenon problems, including problems with uncertain, incomplete, unspecific, or fuzzy situations. Fuzzy set theory is more advantageous than traditional set theory when describing set concepts in human language. It allows us to address unspecific and fuzzy characteristics by using a membership function that partitions a fuzzy set into subsets of members that "incompletely belong to" or "incompletely do not belong to" a given subset [5]. This theory provides a different way to view the problem of modeling uncertainty and offers a wide range of computational tools to aid decision-making [11].

A major contribution of fuzzy set theory is its capability of representing vague data. The theory also allows mathematical operators and programming apply to the fuzzy domain. A fuzzy set is a class of objects with a continuum of grades of membership. Such a set is characterized by a membership (characteristic) function, which assigns to each object a grade of membership ranging between zero and one [10].

\subsection{Fuzzy Number and Fuzzy Linguistic Variable}

We order the universe of discourse such that $U$ is a collection of targets, where each target in the universe of discourse is called an element. A fuzzy number $\tilde{A}$ is mapped onto $\mathrm{U}$ such that a random $U \rightarrow x$ is appointed a real number, 
$\mu_{\tilde{A}}(x) \rightarrow[0,1]$. If another element in $\mathrm{U}$ is greater than $\mathrm{x}$, we call that element under A.

The universe of real numbers $\mathrm{R}$ is a triangular fuzzy number, $\tilde{A}$, which means that for $x \in R, \mu_{\tilde{A}}(x) \in[0,1]$ and

$$
\mu_{\tilde{A}}(x)=\left\{\begin{array}{cl}
(x-L) /(M-L), & L \leq x \leq M, \\
(U-x) /(U-M), & M \leq x \leq U, \\
0, & \text { otherwise }
\end{array}\right.
$$

Note that $\tilde{A}=(L, M, U)$, where $\mathrm{L}$ and $\mathrm{U}$ represent fuzzy probability between the lower and upper boundaries, respectively, as in Figure 5.

Assume two fuzzy numbers $\tilde{A}_{1}=\left(L_{1}, M_{1}, U_{1}\right)$ and $\tilde{A}_{1}=\left(L_{2}, M_{2}, U_{2}\right)$; then:

(1) $\tilde{A}_{1} \oplus \tilde{A}_{2}=\left(L_{1}, M_{1}, U_{1}\right) \oplus\left(L_{2}, M_{2}, U_{2}\right)=\left(L_{1}+L_{2}, M_{1}+M_{2}, U_{1}+U_{2}\right)$

(2) $\tilde{A}_{1} \otimes \tilde{A}_{2}=\left(L_{1}, M_{1}, U_{1}\right) \otimes\left(L_{2}, M_{2}, U_{2}\right)=\left(L_{1} L_{2}, M_{1} M_{2}, U_{1} U_{2}\right)$, $L_{i}>0, M_{i}>0, U_{i}>0$

(3) $\tilde{A}_{1}-\tilde{A}_{2}=\left(L_{1}, M_{1}, U_{1}\right)-\left(L_{2}, M_{2}, U_{2}\right)=\left(L_{1}-L_{2}, M_{1}-M_{2}\right.$, $\left.U_{1}-U_{2}\right)$

(2) $\tilde{A}_{1} \div \tilde{A}_{2}=\left(L_{1}, M_{1}, U_{1}\right) \div\left(L_{2}, M_{2}, U_{2}\right)=\left(L_{1} / L_{2}, M_{1} / M_{2}, U_{1} / U_{2}\right)$, $L_{i}>0, M_{i}>0, U_{i}>0$

$\tilde{A}_{1}^{-1}=\left(L_{1}, M_{1}, U_{1}\right)^{-1}=\left(1 / U_{1}, 1 / M_{1}, 1 / L_{1}\right), L_{i}>0, M_{i}>0, U_{i}>0$

The fuzzy linguistic variable is a variable that reflects different aspects of human language. Its value represents the range from natural to artificial language. When the values or meanings of a linguistic factor are being reflected, the resulting variable must also reflect appropriate modes of change for that linguistic factor. Moreover, variables describing a human word or

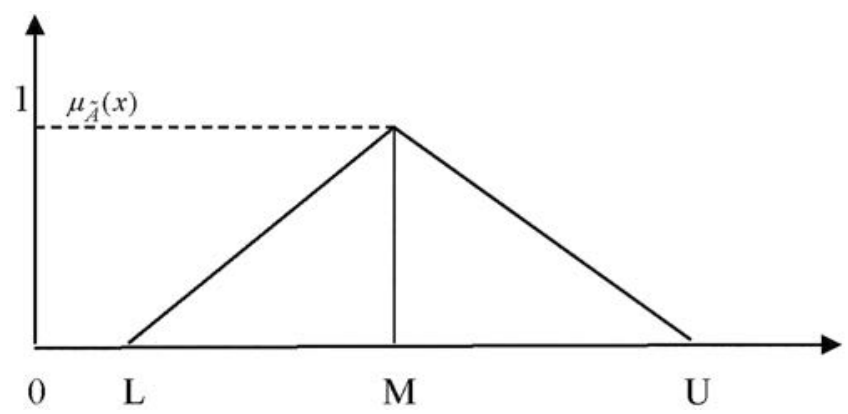

Figure 5 Triangular fuzzy number (Chen \& Chen, 2010). 


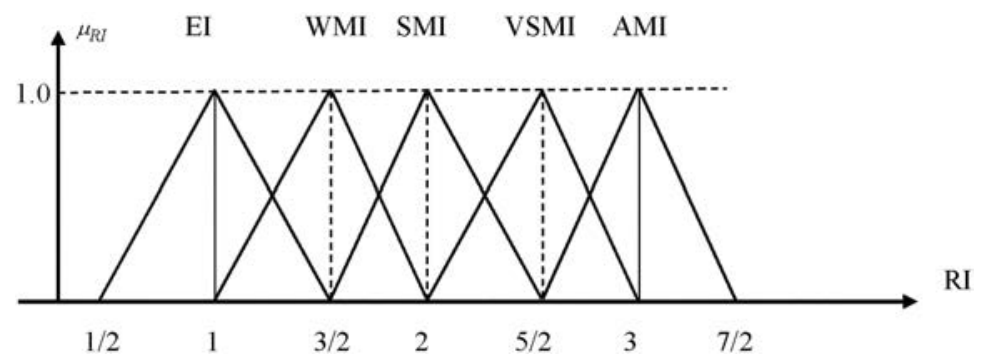

Figure 6 Linguistic scale for relative importance (Kahraman et al., 2006).

Table 4 Linguistic scales for importance (Kahraman et al., 2006)

\begin{tabular}{lcc}
\hline Linguistic Scale for Importance & Triangular Fuzzy & $\begin{array}{c}\text { Triangular Fuzzy } \\
\text { Reciprocal Scale }\end{array}$ \\
\hline Just equal & Scale & $(1,1,1)$ \\
Equally important (EI) & $(1 / 2,1,3 / 2)$ & $(2 / 3,1,2)$ \\
Weakly more important (WMI) & $(1,3 / 2,2)$ & $(1 / 2,2 / 3,1)$ \\
Strongly more important (SMI) & $(3 / 2,2,5 / 2)$ & $(2 / 5,1 / 2,2 / 3)$ \\
Very strongly more important (VSMI) & $(2,5 / 2,3)$ & $(1 / 3,2 / 5,1 / 2)$ \\
Absolutely more important (AMI) & $(5 / 2,3,7 / 2)$ & $(2 / 7,1 / 3,2 / 5)$ \\
\hline
\end{tabular}

sentence can be divided into numerous linguistic criteria, such as equally important, moderately important, strongly important, very strongly important, and extremely important, as shown in Figure 6; definitions and descriptions are shown in Table 4. For the purposes of the present study, the 6-point scale (just equal, equally important, moderately important, strongly important, very strongly important and extremely important) proposed by [10] is used.

\subsection{The Fuzzy VIKOR Method}

Multi Criteria Optimization and Compromise Solution methods (or VIKOR) has been developed for multi-criteria optimization in a complex system. It determines the compromise solution and best solution from a set of alternatives. Compromise solution will be presented by comparing the degree of closeness to the ideal alternative and each alternative can be evaluated by each criterion function. A systematic approach of a fuzzy VIKOR method for multi criteria in fuzziness environment is given in this section. According Tzeng et al. this approach aims to find the best compromise solution between decision-makers to be consistent with the objectives of human cognition. VIKOR algorithm based on modified fuzzy numbers stated as follows: 
Step 1: Expressed multi criteria decision-making problem in the matrix format.

There are $\mathrm{m}$ alternatives can defined as $A_{i}(i=1,2, \ldots, m)$ which will be evaluated based on the criteria selected that is $C_{j}(j=1,2, \ldots, n)$ each criteria has five grade achievement $g=1,2, \ldots, 5$. Subjective evaluation is done to determine the decision matrix

$$
X=\left\{x_{i j g}, i=1,2, \ldots, m ; j=1,2, \ldots, n ; g=1,2, \ldots, 5\right\}
$$

Using linguistic variable as shown in Table 1.

Decision matrix can be expressed as follows:

$$
\begin{aligned}
& \begin{array}{llll}
c_{1} & c_{2} & \cdots & c_{n}
\end{array} \\
& X=\begin{array}{c}
A_{1} \\
A_{2} \\
\vdots \\
A_{m}
\end{array}\left[\begin{array}{cccc}
x_{11} & x_{12} & \cdots & x_{1 n} \\
x_{21} & x_{22} & \cdots & x_{2 n} \\
\vdots & \vdots & \vdots & \vdots \\
x_{m 1} & x_{m 2} & \cdots & X_{\min }
\end{array}\right], \quad i=1,2, \ldots, m ; j=1,2, \ldots, n \\
& W=\left[w_{1}, w_{2}, \ldots, w_{n}\right]
\end{aligned}
$$

Where $A_{1}, A_{2}, \ldots, A_{m}$ are the alternatives to be chosen, $C_{1}, C_{2}, \ldots, C_{m}$ are the evaluation criteria, $x_{i j}$ is the rating of alternative $A_{i}$ with respect to $C_{j}, w_{j}$ is the importance weight of the $j$ criterion holds.

Step 2: Construct a fuzzy decision matrix.

The aggregated fuzzy rating $x_{i j g}$ of alternatives with respect to trapezoidal fuzzy numbers is modification from the method of arithmetic weighted average and calculated using the following equation:

$$
\begin{aligned}
& \tilde{X}=\sum_{i=1}^{m} \sum_{j=1}^{n} \sum_{g=1}^{5} x_{i j g} \otimes T z F N=\left[\tilde{X}_{i j}\right]_{m \times n}=\left[\begin{array}{cccc}
\tilde{x}_{11} & \tilde{x}_{12} & \cdots & \tilde{x}_{1 n} \\
\tilde{x}_{21} & \tilde{x}_{22} & \cdots & \tilde{x}_{2 n} \\
\vdots & \vdots & \vdots & \vdots \\
\tilde{x}_{m 1} & \tilde{x}_{m 2} & \cdots & \tilde{x}_{m n}
\end{array}\right] \\
& \tilde{W}=\left[\tilde{w}_{1}, \tilde{w}_{2}, \ldots, \tilde{w}_{n}\right]
\end{aligned}
$$

This method is most often used an aggregation process because of simple and flexible operations and fits well with the goals of the study. $\tilde{x}_{i j}$ and $\tilde{w}_{j}$ are linguistic variables denoted by trapezoidal fuzzy number where $\tilde{x}_{i j}$ is the rating of alternative $A_{i}$ with respect to $C_{j}, \tilde{w}_{j}$ is the importance weight of the $j$ criterion. A trapezoidal fuzzy number can be defined as

$$
\tilde{x}_{i j}=\left(\tilde{a}_{i j}, \tilde{b}_{i j}, \tilde{c}_{i j}, \tilde{d}_{i j}\right)
$$


Step 3: Evaluate the fuzzy importance weight of criteria.

The fuzzy weighted values for each criterion will be determined based on the importance of each criterion. Degree of importance of each criterion depends on the burden borne by each school. Relative value is directly proportional to the number of candidates sitting for specific subjects. This clearly shows the value of a higher weight should be given to the criteria that have more number of candidates because it brings an additional burden to ensure that each candidate can understand the subject well. Therefore, if the number of candidates taking the subject $j$, then the fuzzy importance of subjects is given as specified by Diakoulaki et al.:

$$
\tilde{w}_{j}=\tilde{s}_{j} / \sum_{j=1}^{n} \tilde{s}_{j}
$$

$\tilde{s}_{j}$ is the standard deviation value for the criterion $C_{n}$. Standard deviation $\tilde{s}_{j}$ is given as follows:

$$
\tilde{s}_{j}=\sqrt{\frac{1}{M} \sum_{m=1}^{M}\left(\tilde{x}_{m n}-\overline{\tilde{x}}_{n}\right)^{2}}
$$

with $\overline{\tilde{x}}=\frac{1}{M} \sum_{m=1}^{M} \tilde{x}_{m n}, 0 \leq \tilde{w}_{j} \leq 1$ and $\mathrm{M}=$ Total number of alternative.

Step 4: Determine the fuzzy best value $\left(\tilde{x}_{j}^{*}\right)$ and fuzzy worst value $\left(\tilde{x}_{j}^{-}\right)$

$$
\begin{gathered}
\tilde{x}_{j}^{*}=\max _{i} \tilde{x}_{i j}, \\
\tilde{x}_{j}^{-}=\min _{i} \tilde{x}_{i j} .
\end{gathered}
$$

Step 5: Compute the normalized fuzzy decision matrix. The normalized fuzzy decision matrix is calculated to ensure that each criterion value between 0 and 1 , so that all the criteria are the standard and are comparable with each other. In this situation, VIKOR method using linear normalization to stabilize. Linear normalization formula indicated by the score $\tilde{S}_{i}$ and $\tilde{R}_{i}$ as follows:

$$
\tilde{S}_{i}=\sum_{j=1}^{n} \tilde{w}_{j}\left(\frac{\tilde{x}_{j}^{*}-\tilde{x}_{i j}}{\tilde{x}_{j}^{*}-\tilde{x}_{j}^{-}}\right) \quad \text { and } \quad \tilde{R}_{i}=\operatorname{Max}_{j}\left[\tilde{w}_{j}\left(\frac{\tilde{x}_{j}^{*}-\tilde{x}_{i j}}{\tilde{x}_{j}^{*}-\tilde{x}_{j}^{-}}\right)\right]
$$


Step 6: Compute the index VIKOR $\tilde{Q}_{i}$

$$
\begin{aligned}
& \tilde{Q}_{i}=v\left(\frac{\tilde{S}_{i}-\tilde{S}^{-}}{\tilde{S}^{+}-\tilde{S}^{-}}\right)+(1-v)\left(\frac{\tilde{R}_{i}-\tilde{R}^{-}}{\tilde{R}^{+}-\tilde{R}^{-}}\right) \\
& \tilde{S}^{+}=\max _{i} \tilde{S}_{i}, \tilde{S}^{-}=\min _{i} \tilde{S}_{i}
\end{aligned}
$$

Where

$$
R^{+}=\max _{i} \tilde{R}_{i}, \tilde{R}^{-}=\min _{i} \tilde{R}_{i}
$$

$v$ is introduced as the weight in strategy of the maximum group utility. From the literature, it has been inferred that the VIKOR index value is mostly taken as $v=0.5$.

Step 7: Sorting the value $\tilde{S}, \tilde{R}$ and $\tilde{Q}$ in descending order. The best alternative in order of $\tilde{Q}$ is the maximum possible value of $\tilde{Q}$ based on merit points that was done in this study and symbolized $A^{(1)}$. With the second largest alternative referred to $A^{(2)}$ and so on until an alternative with the smallest value of $\tilde{Q}$ is expressed as $A^{(m)}$.

Step 8: The alternatives $A^{(1)}$ that are in the best position with the maximum value of $\tilde{Q}$ will be proposed as the best alternatives in providing a compromise solution if and only if satisfy two conditions: C1: Acceptable advantage.

The alternative $A^{(1)}$ accepted as the best advantages when the difference index VIKOR $\tilde{Q}$ between alternative $A^{(2)}$ and $A^{(1)}$ must be greater than or equal to the value of $D Q$, or in other words

$$
\tilde{Q}_{\left(A^{(2)}\right)}-\tilde{Q}_{\left(A^{(1)}\right)} \geq D Q \quad \text { with } D Q=\frac{1}{M-1}
$$

C2: Acceptable stability in decision-making.

Alternative $A^{(i)}$ must also be in the best ranked by $\tilde{S}$ or $\tilde{R}$.

When one of the conditions is not satisfied, a set of compromise solution will be proposed as follows:

i. If $\mathbf{C 1}$ is not satisfied:

Then the alternative set $A^{(1)}, A^{(2)}, \ldots, A^{(m)}$ considered together with its best $A^{(m)}$ determined by the relationship $\tilde{Q}_{\left(A^{(m)}\right)}-\tilde{Q}_{\left(A^{(1)}\right)}<D Q$.

ii. If $\mathbf{C 2}$ is not satisfied:

Thus, both alternative $A^{(1)}$ and $A^{(2)}$ are recommended as the best option position or in other words, the two alternative can be described as the best alternative. R software 2:15 was used to analyses data using fuzzy VIKOR method. 
56 M. Majd et al.

\section{Case Study}

In this study, Our Committee tried to use real data of IKCO Manufacturing sites for selection of the best RIR combination and their locations. It is aim to evaluate and rank the RIR and their locations containing multiple conflicting criteria subject. Based on the results obtained by using F-VIKOR Technique are shown in Tables 5-9:

Table 5 Results for RIR combination selection

\begin{tabular}{lcc}
\hline RIR Combination & & \\
Alternatives & $\tilde{Q}_{i}($ index VIKOR $)$ & Ranking \\
\hline A1 & 0.817 & 2 \\
A2 & 0.632 & 5 \\
A3 & 0.928 & 1 \\
A4 & 0.427 & 8 \\
A5 & 0.365 & 9 \\
A6 & 0.681 & 4 \\
A7 & 0.352 & 10 \\
A8 & 0.474 & 7 \\
A9 & 0.738 & 3 \\
A10 & 0.528 & 6 \\
\hline
\end{tabular}

Table 6 Results for RIR \& CRD Locating in LOZ-2

\begin{tabular}{|c|c|c|c|c|c|}
\hline \multicolumn{3}{|c|}{ RIR Locating in LOZ-2 } & \multicolumn{3}{|c|}{ CRD Locating in LOZ-2 } \\
\hline \multicolumn{3}{|c|}{$\tilde{Q}_{i}($ index } & \multicolumn{3}{|c|}{$\tilde{Q}_{i}($ index } \\
\hline Alternatives & VIKOR) & Ranking & Alternatives & VIKOR) & Ranking \\
\hline$\overline{\mathrm{A} 1}$ & 0.717 & 3 & A1 & 0.741 & 3 \\
\hline A2 & 0.572 & 6 & $\mathrm{~A} 2$ & 0.575 & 6 \\
\hline A3 & 0.767 & 2 & A3 & 0.883 & 1 \\
\hline A4 & 0.661 & 4 & A4 & 0.695 & 4 \\
\hline A5 & 0.658 & 5 & A5 & 0.817 & 2 \\
\hline A6 & 0.823 & 1 & A6 & 0.611 & 5 \\
\hline
\end{tabular}

Table 7 Results for RIR (Tehran-Babol) \& HUB Locating in C-LOZ

\begin{tabular}{lccccc}
\hline \multicolumn{2}{l}{ RIR Locating in C-LOZ (Tehran-Babol) } & \multicolumn{3}{c}{ HUB Locating in C-LOZ } \\
\hline & $\tilde{Q}_{i}($ index & & & $\tilde{Q}_{i}($ index \\
Alternatives & VIKOR $)$ & Ranking & Alternatives & VIKOR $)$ & Ranking \\
\hline A1 & 0.984 & 1 & A1 & 0.773 & 3 \\
A2 & 0.727 & 6 & A2 & 0.864 & 1 \\
A3 & 0.911 & 2 & A3 & 0.831 & 2 \\
A4 & 0.853 & 3 & A4 & 0.742 & 4 \\
A5 & 0.766 & 5 & A5 & 0.686 & 6 \\
A6 & 0.817 & 4 & A6 & 0.716 & 5 \\
\hline
\end{tabular}


Table 8 Results for RIR Locating in C-LOZ (Tehran-Fars)

\begin{tabular}{lcc}
\multicolumn{3}{c}{ RIR Locating in C-LOZ (Tehran-Fars) } \\
\hline Alternatives & $\tilde{Q}_{i}($ index VIKOR $)$ & Ranking \\
\hline A1 & 0.775 & 5 \\
A2 & 0.928 & 1 \\
A3 & 0.881 & 2 \\
A4 & 0.815 & 4 \\
A5 & 0.843 & 3 \\
A6 & 0.736 & 6 \\
\hline
\end{tabular}

Table 9 Results for RIR \& CRD Locating in LOZ-3

\begin{tabular}{lccccc}
\hline \multicolumn{3}{c}{ RIR Locating in LOZ-3 } & \multicolumn{4}{c}{ CRD Locating in LOZ-3 } \\
\hline Alternatives & $\tilde{Q}_{i}($ index VIKOR $)$ & Ranking & Alternatives & $\tilde{Q}_{i}($ index VIKOR $)$ & Ranking \\
\hline A1 & 0.794 & 3 & A1 & 0.774 & 2 \\
A2 & 0.762 & 4 & A2 & 0.711 & 3 \\
A3 & 0.719 & 6 & A3 & 0.652 & 5 \\
A4 & 0.675 & 5 & A4 & 0.683 & 4 \\
A5 & 0.851 & 1 & A5 & 0.614 & 6 \\
A6 & 0.822 & 2 & A6 & 0.828 & 1 \\
\hline
\end{tabular}

\section{IOLN Design}

According to results obtained by analyzing the data by using F-Vikor Technique, The optimal combination of RIR was selected as follows: HUB, CRD and RPP (Table 5). In addition, the most optimal locations were chosen, in the following, the proposed design for IOLN is shown in Figures 7 and 8:

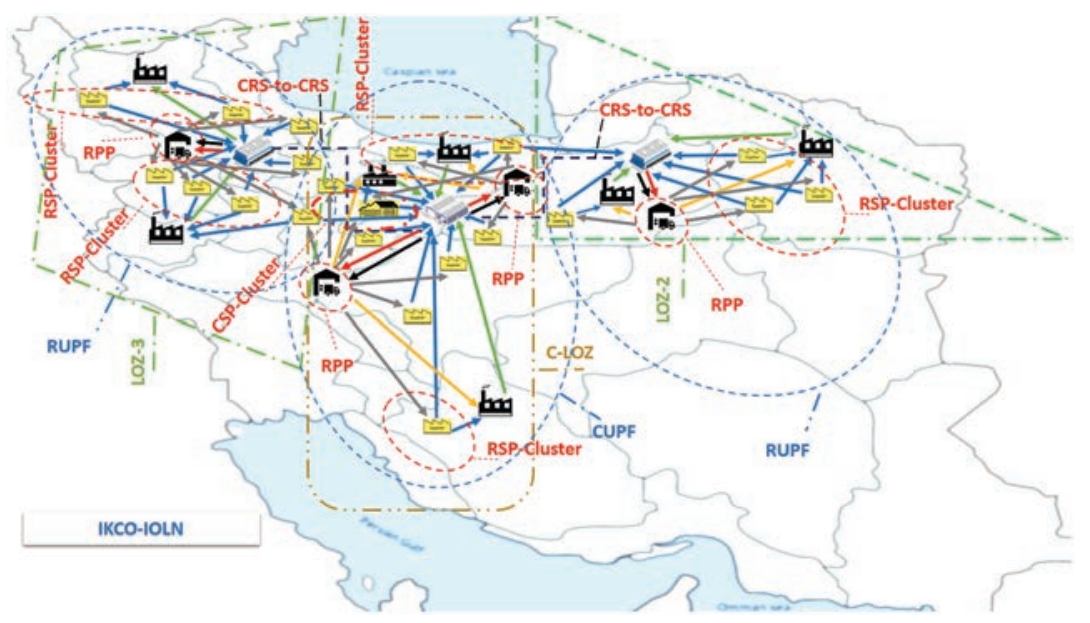

Figure 7 IOLN Design (Operational Glance). 


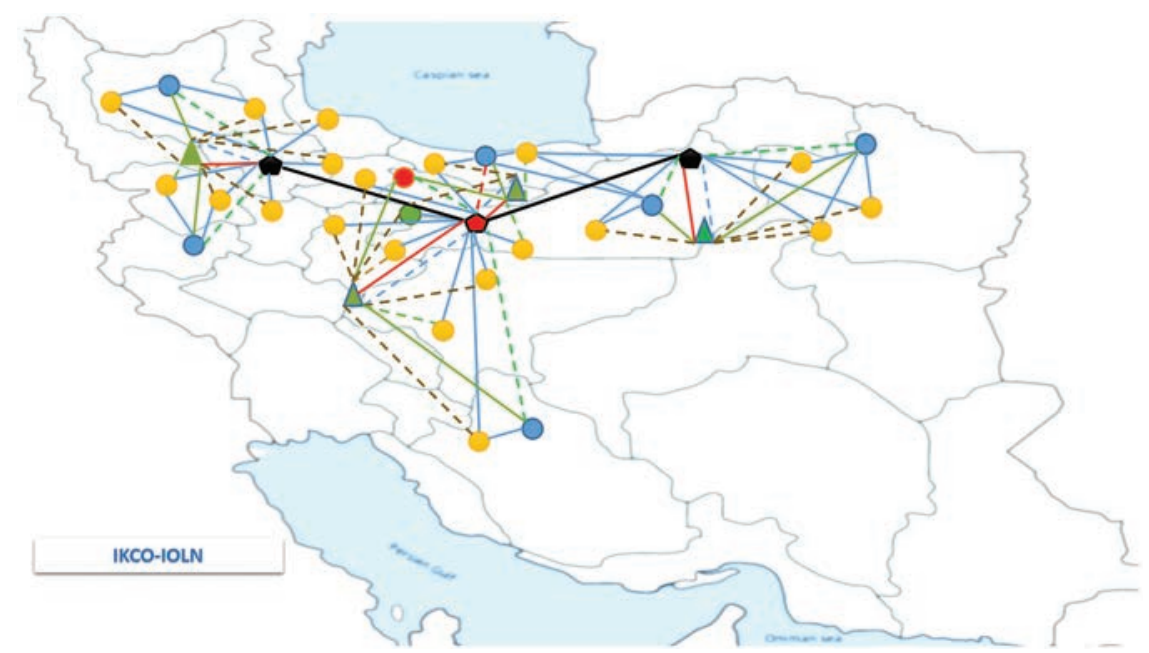

Figure 8 IOLN Design (Clustered Glance).

Table 10 IOLN legend

\begin{tabular}{|c|c|c|c|c|c|c|}
\hline Symbols & $\begin{array}{l}\text { Freight } \\
\text { Shipping } \\
\text { Service } \\
\text { (FSS) } \\
\end{array}$ & Explanation & Symbols & Explanation & Symbols & Explanation \\
\hline & TL & $\begin{array}{c}\text { Transportation of } \\
\text { Consumable Parts } \\
\text { (TCP) }\end{array}$ & 高 & $\begin{array}{l}\text { Central Site } \\
\text { (CS) }\end{array}$ & & $\begin{array}{l}\text { Regional } \\
\text { Supplier } \\
\text { (RSU) }\end{array}$ \\
\hline & $\mathrm{TL}$ & TCP & $\underline{E}$ & $\begin{array}{c}\text { Regional Site } \\
\text { (RS) }\end{array}$ & & Hub \\
\hline & LTL & TCP & & $\begin{array}{c}\text { Central } \\
\text { Supplier (CSU) }\end{array}$ & & CRD \\
\hline & TL & $\begin{array}{c}\text { Transportation of } \\
\text { Unloaded Pallets } \\
\text { (TUP) }\end{array}$ & 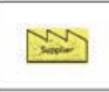 & $\begin{array}{c}\text { Regional } \\
\text { Supplier (RSU) }\end{array}$ & & RPP \\
\hline & TL & TUP & & $\begin{array}{l}\text { Regional Pool } \\
\text { Point (RPP) }\end{array}$ & \multirow{5}{*}{\multicolumn{2}{|c|}{ Legend }} \\
\hline & LTL & TUP & & $\begin{array}{l}\text { Regional Cross } \\
\text { Dock (RCRD) }\end{array}$ & & \\
\hline$---\cdot$ & TL & CRS-to-CRS & & $\begin{array}{c}\text { Central Cross } \\
\text { Dock (CCRD) }\end{array}$ & & \\
\hline$\ldots$ & $\mathrm{TL}$ & TUP & & $\begin{array}{l}\text { Regional Site } \\
\text { (RS) }\end{array}$ & & \\
\hline$---\cdots$ & $\mathrm{TL}$ & TUP & & $\begin{array}{c}\text { Central Site } \\
\text { (CS) }\end{array}$ & & \\
\hline
\end{tabular}

\section{Conclusions and Discussions}

F-VIKOR method is an effective technique for analysing various types of index, and it has been widely used in the rank of alternatives in the field 
of management. The provided case study has demonstrated the capability of the proposed fuzzy MCDM model to effectively solution for the best RIR combination selection and ranking problem under a fuzzy environment. In this method, the ranking of the optimal combination of RIR locations were chosen are assessed in linguistic variable by trapezoidal fuzzy numbers and the importance weights of index are also in fuzzy number. This study used fuzzy VIKOR method to determine the priority ranks of the performance for ten schools. By using the suggested integrated operational logistics network design with novel and practical approach. Based on the results obtained, the analyzing the data by using F-Vikor Technique, shows that the optimal combination of RIR was selected as follows: HUB, CRD and RPP. In addition, the most optimal locations were chosen in each logistics operational zone (LOZ), as follows:

LOZ-2: Shahrud (RPP) and Mayamey (CRD)

C-LOZ (Center and North Section): Garmsar (RPP)

C-LOZ: Robat Karim (HUB)

C-LOZ (Center and South Section): Kashan (RPP)

LOZ-3: Bostanabad (RPP) and Zanjan (CRD)

In addition, the results of this study could provide a reference point for other Industries in their efforts to improve their Logistics network and move to continues optimization of supply chain process. IOLN can help logistics engineers and managers to have a comprehensive logistics network and insight in all over the supply chain. They can with continues analysis IOLN, have a good and enough readiness to responsibility to demand fluctuations and flexibility against the challenges and barriers to just in time supply and identification of critical routes and areas for logistics operations.

\section{References}

[1] Boonitt, S. and Wong, C. Y. (2011). The moderating effects of technological and demand uncertainties on the relationship between supply chain integration and customer delivery performance. International Journal of Physical Distribution and Logistics Management, 41(3), 253-276.

[2] Cai, S., Jun, M., and Yang, Z. (2010). Implementing supply chain information integration in China: the role of institutional forces and trust. Journal of Operations Management, 28(3), 257-268.

[3] Cao, Z., Huo, B., Li, Y., and Zhao, X. (2015). The impact of organizational culture on supply chain integration: A contingency and 
configuration approach. Supply Chain Management: An International Journal, 20(1), 24-41.

[4] Chen, J. K. and Chen, I. S. (2010). A Pro-performance appraisal system for the university. Expert Systems with Applications, 37(3), 2108-2116.

[5] Chen, Z., Huang, Y., and Sternquist, B. (2011). Guanxi practice and Chinese buyer-supplier relationships: The buyer's perspective. Industrial Marketing Management, 40(4), 569-580.

[6] Droge, C., Jayaram, J., and Vickery, S. K. (2004). The effects of internal versus external integration practices on time-based performance and overall firm performance. Journal of Operations Management, 22(6), 557-573.

[7] Flynn, B. B., Koufteros, X., and Lu, G. (2016). On theory in supply chain uncertainty and its implications for supply chain integration. Journal of Supply Chain Management, 52(3), 3-27.

[8] Flynn, B. B., Huo, B., and Zhao, X. (2010). The impact of supply chain integration on performance: A contingency and configuration approach. Journal of Operations Management, 28(1), 58-71.

[9] Jayaram, J., Tan, K.-C., and Nachiappan, S. P. (2010). Examining the interrelationships between supply chain integration scope and supply chain management efforts. International Journal of Production Research, 48(22), 6837-6857.

[10] Kahraman et al. (2003). Fuzzy Applications in Industrial Engineering.

[11] Karmaker, C. and Saha, M. (2015). Optimization of warehouse location through fuzzy multi-criteria decision-making methods. Decision Science Letters 4(3), 315-334.

[12] Khamisabadi, J., eds. (2013). Introducing a model in order to logistics balance with the aim of improving for total expected cost Case Study: Tondar 90 Assembly shop, Iran khodro Co. Journal of Basic and Applied Scientific Research, 3(3), 285-292.

[13] Khamisabadi, J. and Majd, M. (2013). The using of logistic integrated total expected costs models in supply chain management. International Science and Investigation Journal 2(4), 51-56.

[14] Stonebraker, P. W. and Liao, J. (2004). Environmental turbulence, strategic orientation: modeling supply chain integration. International Journal of Operations and Production Management, 24(10), 1037-1054.

[15] Wiengarten, F., Humphreys, P., Gimenez, C., and McIvor, R. (2016). Risk, risk management practices, and the success of supply chain integration. International Journal of Production Economics, 171(Part 3), 361-370. 
[16] Wiengarten, F., Pagell, M., Ahmed, M. U., and Gimenez, C. (2014). Do a country's logistical capabilities moderate the external integration performance relationship? Journal of Operations Management, 32(1-2), $51-63$.

[17] Zhao, X., Huo, B., Selen, W., and Yeung, J. H. Y. (2011). The impact of internal integration and relationship commitment on external integration. Journal of Operations Management, 29(1-2), 17-32.

[18] Zadeh, L. A. (1965). Fuzzy sets. Information and Control, 8(3), $338-352$.

\section{Biographies}

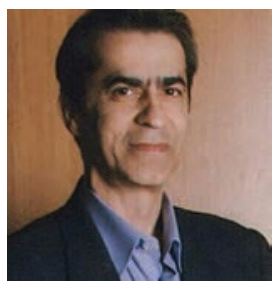

Mahmood Majd is Director of Logistics Management, IKCO,Tehran, Iran

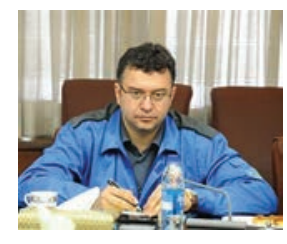

Mohammad Reza Motamed is IKCO - Peugeot CEO, Tehran, Iran. Senior Expert in Production and Logistics Systems.

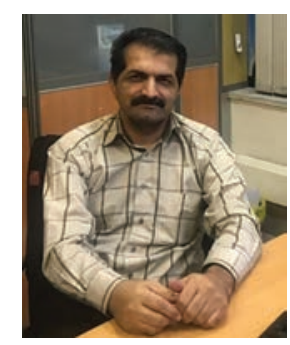

Mohammad Rouhina is Director of Systems Management, IKCO, Tehran, Iran 


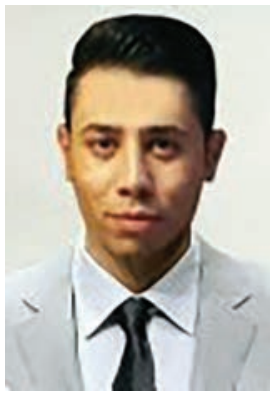

Javad Khamisabadi is Ph.D in industrial Management. (Islamic Azad University, Tehran, Iran)

Expert of Logistics Engineering, ISEIKCO, Tehran, Iran Board Member at Young Scientists Scientific Center \& Honorary Prof, Kharkov, Ukraine

Member of Industrial Engineering and Operation Management Society, Washington, USA

Board Member at WASTINC, Las Vegas, Nevada, USA

Board Member at Entrepreneurship Scientific Center, Moscow, Russia Board Member at Management Scientific Center, WBS Torun University, Poland

Board Member at IAOES, London, UK

Member of Committee at WEASC, Athens, Greece

Board Member at Supply chain management Scientific Center, Sandy Bay, Australia

Board Member at Management Scientific Center, AirLanga University, Indonesia

Faculty of Management, Islamic Azad University, Tehran, Iran 